\title{
Investigation of microleakage of polymerized with LED and halogen light devices four different restorative materials
}

\author{
Ayşe Günay1® ${ }^{\circledR}$, Emin Caner Tümen² \\ ${ }^{1}$ Dicle University, Faculty of Dentistry, Department of Pediatric Dentistry, Diyarbakir, Turkey
}

\section{Correspondence:}

\section{Dr. Ayșe GÜNAY}

Dicle University, Faculty of Dentistry, Department of Pediatric Dentistry, Diyarbakir, Turkey

E-mail:ayok18@hotmail.com

Received: 3 April 2020

Accepted: 2 September 2020

\section{Abstract}

Aim: This study aimed to evaluate the in vitro effects on microleakage of LED and halogen light devices used in the polymerization of monomer structure composite resins of different viscosities and inorganic filling particle size applied to standard class $V$ cavities in primary teeth.

Methodology: 80 non caries primary molar teeth with standard class $v$ cavity on the buccal surfaces were used. The teeth were randomly divided into 4 main groups and restored with composite resins (Herculite ${ }^{\circledR}$ XRV, Ultra ${ }^{T M}$, Filtek ${ }^{T M}$ Silorane, Vertise ${ }^{T M}$ Flow, El Eliteflo $\left.{ }^{T M}\right)$. Each group was divided into 2 sub-groups for polymerization with LED or halogen light devices. Following the thermal cycle and subsequent procedures, the dye penetration method was used to evaluate microleakage. The microleakage scores were evaluated using the Kruskal-Wallis and MannWhitney U-tests.

Results: According to the results of the statistical analysis, in polymerization made with halogen and LED light devices at the occlusal edge, the microleakage scores from lowest to highest were as follows: Filtek $^{T M}$ Silorane $<$ Herculite ${ }^{\circledR}$ XRV Ultra ${ }^{\mathrm{TM}}<\mathbb{A}^{\text {Eliteflo }}{ }^{\mathrm{TM}}<$ Vertise $^{\mathrm{TM}}$ Flow. In polymerization made with halogen and LED light devices at the gingival edge, the microleakage scores from lowest to highest were as follows: Filtek $^{\mathrm{TM}}$ Silorane $<$ Herculite ${ }^{\circledR}$ XRV Ultr ${ }^{\mathrm{TM}}<$ Vertise $^{\mathrm{TM}}$ Flow $<$ /Eliteflo ${ }^{\mathrm{TM}}$.

Conclusion: In the polymerizations made by using LED and halogen light devices, Herculite ${ }^{\circledR}$ XRV Ultra ${ }^{T M}$, was found to be successful as it showed similar values to Filtek ${ }^{\mathrm{TM}}$ Silorane, which gave the best results in terms of microleakage. Moreover, as we have reached similar findings in our thesis study in respect of microleakage, in cases indicating the use of flow composite resin materials such as $\mathbb{E}^{\text {Eliteflo }}{ }^{T M}$, Vertise ${ }^{T M}$ Flow can be used as it has the advantage of ease application and thus provide an ideal alternative in pediatric dentistry.

Keywords: Primary tooth, microleakage, class v cavity, light devices

How to cite this article: Günay A, Tümen EC. Investigation of microleakage of polymerized with LED and halogen light devices four different restorative materials. Int Dent Res 2020;10(3):73-9. https://doi.org/10.5577/intdentres.2020.vol10.no3.2 


\section{Introduction}

In developed societies there has been increasing interest in new approaches to preventative dentistry, a tendency for preparing cavities more conservatively, patients giving more importance to aesthetics, advances in the technology of adhesions and in recent years, the application of tooth colour restoration in posterior regions as much as in anterior regions $(1,2)$. However, in tooth restorations shrinkage may occur during polymerisation of the widely-used resin-based restorative materials, and if the adhesive strength to dentin of the adhesive agents applied to the dentin surface is not strong enough to prevent the negative effects of this shrinkage, a gap is formed in the interface of the tooth and restoration and there is leakage of oral fluids together with micro-organisms from this gap into the cavity $(3,4)$. The potential micro-gap and microleakage developing related to that may cause deeper invasion of micro-organisms into the tooth tissue, postoperative sensitivity, secondary decay and inflammatory changes in the pulp (5). There have been several recent studies which have researched the use of newly developed materials and light devices with different application techniques to eliminate microleakage in composite resin restorations. All of these render microleakage a significant problem which requires discussion and analysis (6-8).

As a result of recent studies and technologies which have been developed, two new composite resin materials have become available for dentists. The first of these is a self-adhesive flow composite resin, Vertise ${ }^{\mathrm{TM}}$ Flow (Kerr Corporation, Orange, CA, USA), and the other is Filtek ${ }^{\text {TM }}$ Silorane (3M ESPE, St.Paul, USA), which is a new cationic ring-opening monomer system restorative material. The manufacturers claim that the silorane structure of this new composite resin shows less polymerisation shrinkage compared to traditional methacrylate-based composite resins and due to the physical and mechanical properties of the developed self-adhesive flow composite resin there will be a broader area of use.

This study aimed to evaluate the in vitro effects on microleakage of LED and halogen light devices used in the polymerization of monomer structure composite resins of different viscosities and inorganic filling particle size applied to standard class $V$ cavities in primary teeth.

\section{Materials and Methods}

In this study, a total of 80 primary molar teeth were used, which were extracted for various reasons (time for removal or persistence) from patients presenting at the Paediatric Dentistry Department of the Dental Faculty at Dicle University.

The soft tissue and remnants were removed from the roots of the extracted teeth with a scraper and the teeth were then cleaned with pumice and polishing brush and stored in distilled water at room temperature. Using cylindrical and reverse conic diamond burrs on the buccal surface under water cooling, all the teeth were then prepared with a standard class $V$ cavity of $2 \mathrm{~mm}$ depth, $2 \mathrm{~mm}$ occlusogingival width, $3 \mathrm{~mm}$ mesio-distal width, $1.5 \mathrm{~mm}$ coronal of the gingival edge of the enamel-cement border in the occlusal edge of the enamel.

A total of 80 cavities were prepared acccording to the stated standards and the burrs were changed after each 5 cavities. The teeth were then randomly allocated to one of 4 groups of 20. Each of the 4 groups was then randomly divided into 2 subgroups. Restorations were applied to all the teethh in the 8 groups according to the manufacturer's recommendations and were polymerised with different light devices (Tables 1, 2 and 3).

Table 1. Materials used in the study

\begin{tabular}{|c|c|c|c|}
\hline Restorative Materials & Type & Manufacturer & Adhesive System \\
\hline $\begin{array}{l}\text { Herculite } ₫ \text { XRV } \\
\text { UltraTM } \\
\text { (HU) }\end{array}$ & $\begin{array}{c}\text { (Nanohybrid } \\
\text { Condensable } \\
\text { Composite Resin) }\end{array}$ & Kerr, Salerno, Italia & $\begin{array}{l}\text { OptiBond All-In-One } \\
\text { (Kerr, Salerno, Italia) }\end{array}$ \\
\hline $\begin{array}{l}\text { Filtek }^{\mathrm{TM}} \text { Silorane } \\
\text { (FS) }\end{array}$ & $\begin{array}{c}\text { (Microhybrid } \\
\text { Condensable } \\
\text { Composite Resin) }\end{array}$ & $\begin{array}{c}\text { 3M ESPE, St.Paul, } \\
\text { U.S.A. }\end{array}$ & $\begin{array}{l}\text { Self-Etch Primer (3M ESPE, } \\
\text { Neuss, Germany), Bond ( } 3 M \\
\text { ESPE, Seefeld, Germany) }\end{array}$ \\
\hline $\begin{array}{c}\text { Vertise }^{T M} \text { Flow } \\
\text { (VF) }\end{array}$ & $\begin{array}{c}\text { (Nanohybrid } \\
\text { Flowable Composite } \\
\text { Resin) }\end{array}$ & Kerr, Orange, CA, USA & - \\
\hline $\begin{array}{l}\text { Eliteflo } \\
\text { (AE) }\end{array}$ & $\begin{array}{c}\text { (Microhybrid } \\
\text { Flowable Composite } \\
\text { Resin) }\end{array}$ & $\begin{array}{c}\text { Bisco, Schaumburg, } \\
\text { USA }\end{array}$ & $\begin{array}{c}\text { One-Step }{ }^{\circledR} \\
\text { (Bisco, Schaumburg, USA) }\end{array}$ \\
\hline
\end{tabular}


Table 2. Study design

\begin{tabular}{|c|c|c|c|c|c|}
\hline Groups & Restorative Materials & Sample Size (n) & Subgoups & Sample Size (n) & Light Devices \\
\hline \multirow[t]{2}{*}{ Group 1} & Herculite® XRV & 20 & $A$ & 10 & Halogen \\
\hline & UltraTM & & B & 10 & LED \\
\hline \multirow[t]{2}{*}{ Group 2} & Filtek $^{T M}$ Silorane & 20 & A & 10 & Halogen \\
\hline & & & B & 10 & LED \\
\hline \multirow[t]{2}{*}{ Group 3} & Vertise $^{T M}$ Flow & 20 & A & 10 & Halogen \\
\hline & & & B & 10 & LED \\
\hline \multirow[t]{2}{*}{ Group 4} & Eliteflo ${ }^{T M}$ & 20 & A & 10 & Halogen \\
\hline & & & B & 10 & LED \\
\hline
\end{tabular}

Table 3. Light devices used in the study

\begin{tabular}{ccc}
\hline Light Devices & Manufacturer & Light Intensity \\
\hline Monitex Blue Luxcer & Monitex, Taipei, Taiwan & $>1000 \mathrm{~mW} / \mathrm{cm}^{2}$ \\
(Halogen Light Device) & \\
Henry Schein HS-LED 1500 (LED & Henry Schein Inc., Melville, USA & $>1500 \mathrm{~mW} / \mathrm{cm}^{2}$
\end{tabular}

Light Device)

After the finishing and polishing procedures, all the teeth were incubated at $37^{\circ} \mathrm{C}$ for 24 hours. All the teeth were then kept for 30 secs in heat baths using tap water of $5^{\circ} \mathrm{C}-55^{\circ} \mathrm{C}\left( \pm 2^{\circ} \mathrm{C}\right)$ and 1000 thermal cycle procedure was applied (NOVA, Konya, Turkey). Following the thermal cycle application, the root tips, furcation points, areas of resorption and all points which could negatively affect the microleakage test were closed with a flow composite resin (Filtek Supreme XT Flow, 3M ESPE).

Two layers of nail varnish (Flormar, Kocaeli, Turkey) were applied to all the teeth $1 \mathrm{~mm}$ outside the cavity border and they were then left to harden.

Following this procedure, all the samples were left in $0.5 \%$ basic fuchsine solution for 24 hours. The teeth were then washed in running water to remove the remaining stain and were dried at room temperature. The teeth were cut in the centre of the restorations in the buccolingual direction with a slicing device (Isomet Buehler, Illinois, US) under water cooling. The surfaces of the samples to be examined under microscope were sanded with water sandpaper. The leakage values of the surfaces of the slices obtained were examined at X20 magnification with a stereomicroscope (SZ-PT Olympus, Japan).

Evaluation of the leakage values of the surfaces of the slices obtained was made by 2 independent researchers according to the scoring system below (9) (Fig. 1).

$0:$ No marginal leakage;

1: Dye penetration within $1 / 3$ of the cavity wall;

2: Dye penetration within $2 / 3$ of the cavity wall;

3: Dye penetration within the last $1 / 3$ of the cavity wall without reaching the axial wall;

4: Dye penetration spreading along the axial wall.

\section{Statistical Analysis}

In this study in which microleakages from 4 different restorative materials polymerised with halogen and LED light devices were examined with the dye penetration method, in the comparison of the microleakage scores between groups, the KruskalWallis test was used and in the paired comparisons, the Mann Whitney U-test as a non-parametric statistical test. A value of $p<0.05$ was accepted as statistically significant.

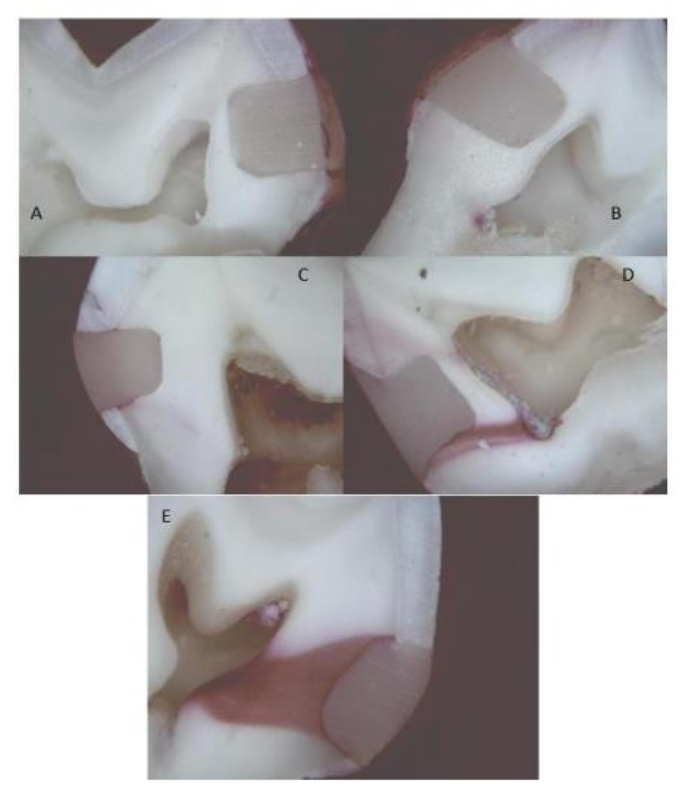

Figure 1. Dye penetration scores to 0 from 4. 


\section{Results}

The leakage values of the surfaces of the slices obtained were examined at $\times 20$ magnification with a stereomicroscope.

In the Kruskal-Wallis test evaluation of all the 8 groups in the study, a statistically significant difference was seen in the microleakage values of the occlusal and gingival edges $(p<0.05)$ (Graphs 1 and 2$)$.

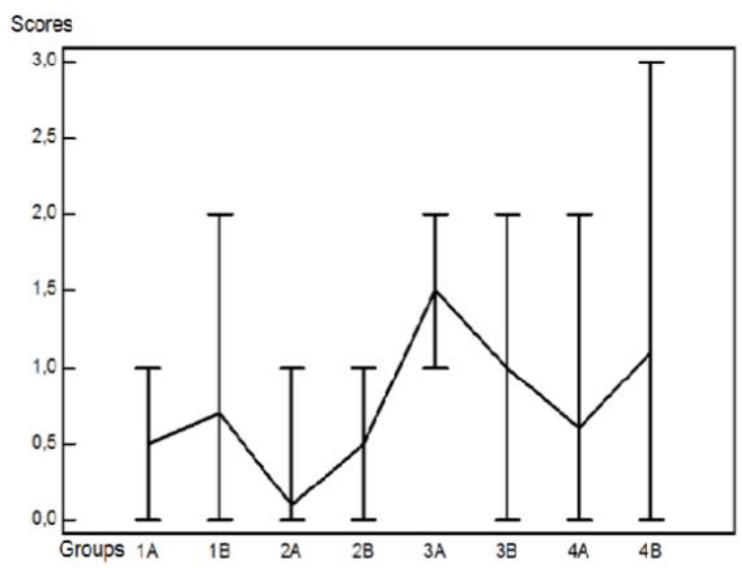

Graphic 1. The change in the microleakage values in the occlusal edges of the restorative materials used in the study.

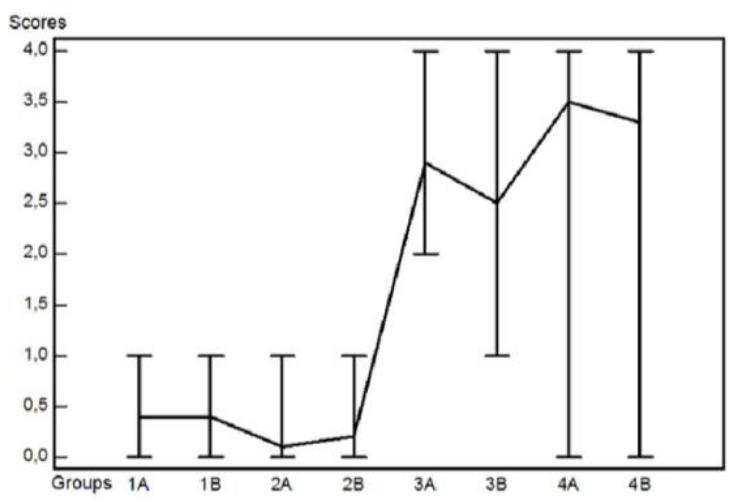

Graphic 2. The change in the microleakage values in the gingival edges of the restorative materials used in the study

In the occlusal edge evaluation made as a result of the application of this test, the microleakage values of Group 2A (FS polymerised with halogen light device) were determined to be statistically significantly lower than those of Groups 1B, 3A, 3B and 4B $(p<0.05)$. The microleakage values in the occlusal edge were seen to be highest in Group 3A (VF polymerised with halogen light device) and a statistically significant difference was determined compared to Groups 1A, 1B, 2A, 2B and $4 A(p<0.05)$.

In the gingival edge evaluation, the microleakage values of Group 2A (FS polymerised with halogen light device) were determined to be statistically significantly lower than those of Groups 3A, 3B, 4A and
$4 B(p<0.05)$. The microleakage values in the occlusal edge were seen to be highest in Group 4A ( $\mathbb{E}$ polymerised with halogen light device) and a statistically significant difference was determined compared to Groups $1 A, 1 B, 2 A$ and $2 B(p<0.05)$.

When the microleakage values in the occlusal and gingival edges were compared taking into account all the materials used, it was determined that statistically significantly more leakage occurred in the gingival edge (mean rank 90.04) than in the occlusal edge (mean rank 70.96) $(\mathrm{p}<0.05)$.

Comparison of the leakage values in the occlusal and gingival edges of the composite resin groups according to the different light devices within the same group was made using Mann-Whitney $\mathrm{U}$ test.

When evaluation was made within the same group of the microleakage results in the occlusal edge, a lower microleakage value was seen in Group 3 with LED light device and a statistically significant difference was determined between the halogen and LED light devices $(p=0.042)$. Although lower microleakage values were obtained with the use of halogen light device in Groups 1, 2 and 4, no statistically significant difference was determined between the halogen and LED light devices $(p>0.05)$.

When evaluation was made within the same group of the microleakage results in the gingival edge, although lower microleakage values were obtained with the use of halogen light device in Groups 3 and 4 with LED light device, and in Group 2 with halogen light device, no statistically significant difference was determined between the halogen and LED light devices in respect of leakage $(p>0.05)$. In Group 1, the microleakage values of both light devices were determined to be equal.

In the composite resin groups polymerised with halogen light device, the highest leakage values in the occlusal edge were observed to be in VF and a statistically significant difference was determined between this group and the other composite resins $(p<0.05)(G r a p h 3)$.

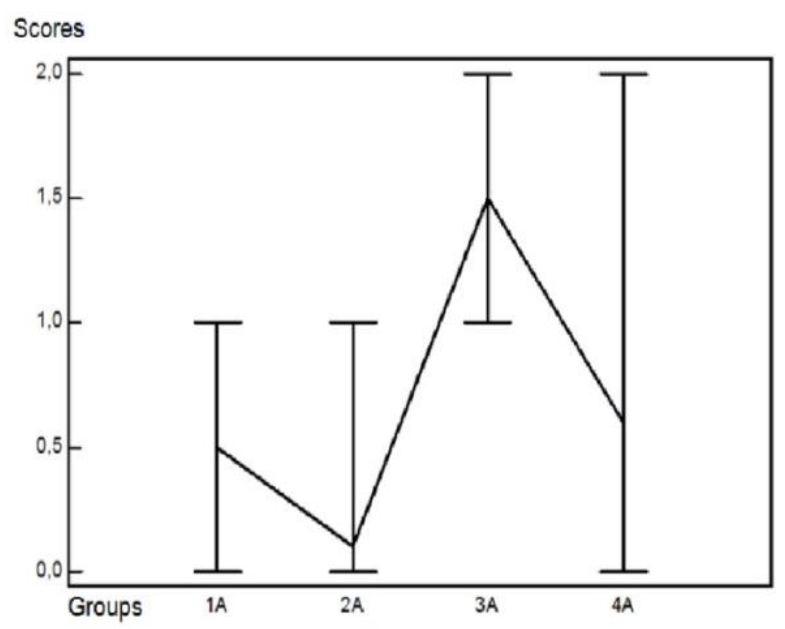

Graphic 3. Comparison of the composite resin groups polymerised with halogen light device in respect of the occlusal edge leakage scores. 
In the composite resin groups polymerised with halogen light device, a statistically significant difference was determined between FS\&HU, showing the lowest values in the gingival edge, and $\mathbb{E} \& V F$, showing the highest values $(p<0.05)(G r a p h 4)$.

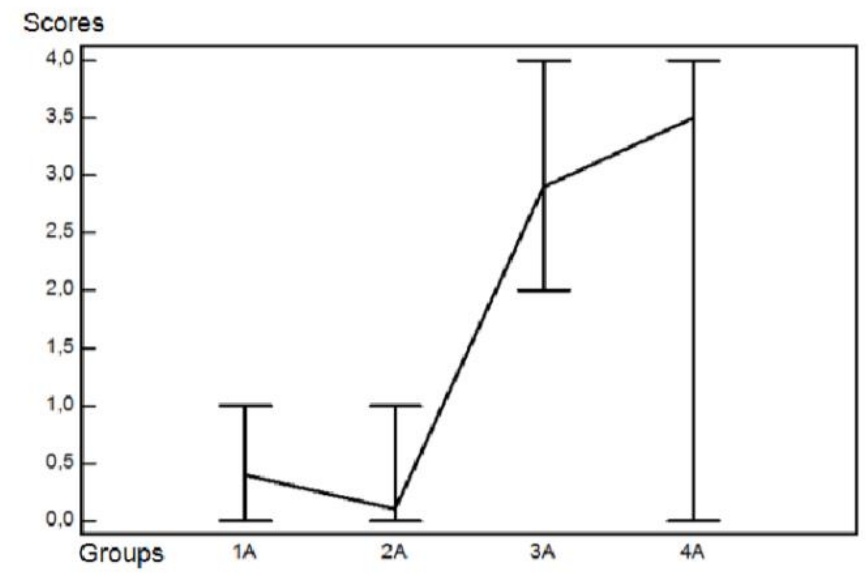

Graphic 4. Comparison of the composite resin groups polymerised with halogen light device in respect of the gingival edge leakage scores.

In the composite resin groups polymerised with LED light device, the microleakage values in the occlusal edge no statistically significant difference was determined between the composite resins $(p>0.05)$ (Graphic 5).

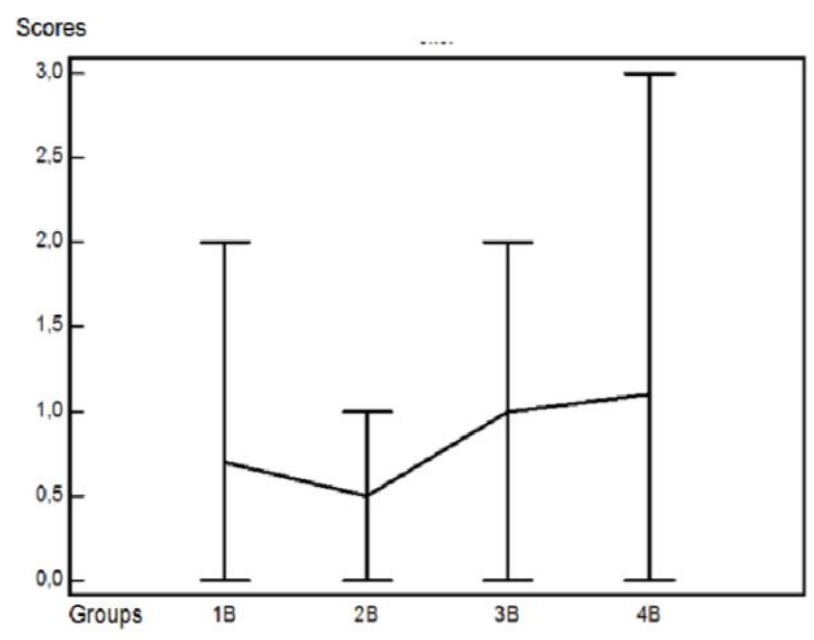

Graphic 5. Comparison of the composite resin groups polymerised with LED light device in respect of the occlusal edge leakage scores.

In the composite resin groups polymerised with LED light device, a statistically significant difference was determined between FS\&HU, showing the lowest values in the gingival edge, and $\mathbb{E E V F}$, showing the highest values $(p<0.05)$ (Graph 6).

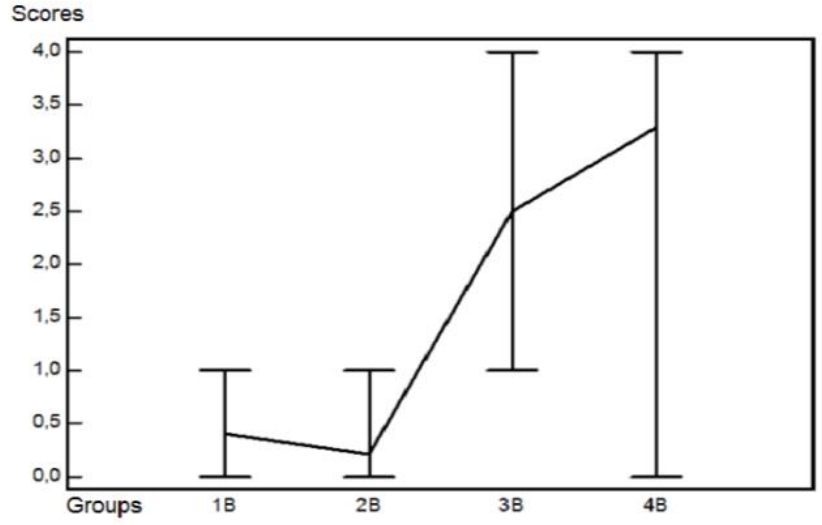

Graphic 6. Comparison of the composite resin groups polymerised with LED light device in respect of the gingival edge leakage scores.

\section{Discussion}

Newly-developed materials to be able to eliminate microleakage in composite resin restorations used with light devices and different application techniques are the subject of several current research studies.

The aim of the present study was to obtain data related to microleakage which could develop in restorative materials polymerised with different light devices by testing the reliability of newly-developed materials in respect of paediatric dentistry.

Another point which is just as important for the success of restorations as the types of adhesive and composite used, is the use of the light device. Light devices in current use are ultraviolet, quartz-tungstenhalogen, light-emitting diode, laser and plasma arc (10).

In the current study, the widely used halogen and LED light devices were used for the polymerisation of dental restorative materials. In the evaluation of the findings of the current study, the lowest leakage values in both the occlusal and gingival edges in all 8 groups were obtained with FS. When FS was polymerised with both halogen and LED light devices, the lowest leakage values were again obtained (Groups $2 \mathrm{~A}$ and $2 \mathrm{~B}$ ). In a study by Weinmann et al, 4 different methacrylatebased composites were compared with FS. Less polymerisation shrinkage was seen in the FS group compared to all the other groups (11). In a study by Poureslami et al., FS was compared with 3 types of composite resin on primary teeth and the best group in respect of microleakage was reported to be silorane applied with acidification (12). Similar to our study, many studies have reported that FS shows less leakage than methacrylate-based composites $(13,14)$.

In the currrent study, the highest leakage values in the occlusal edge were seen in the newlydeveloped self-adhesive flow composite, VF, in all 8 groups. When VF was polymerised with both halogen and LED light devices, the highest leakage values were again obtained (Groups $3 \mathrm{~A}$ and $3 \mathrm{~B}$ ). While this difference was not statistically significant when polymerisation was applied with the LED light device 
$(p>0.05), \quad$ a statistically significant difference was determined with the use of the halogen light device $(p<0.05)$. In a study by Boutsiouki et al., flow textured composites were applied as overlay on pits and fissures and microleakage was evaluated. The most microleakage was observed in the VF group (15). Another study parallel to our finding is that Eliades et al. investigated that flow restorative materials were evaluated as pit and fissure sealants, and that the highest microleakage values were observed in selfadhesive flow composites (16).

In the evaluation of the gingival edge in the current study, the VF group showed a greater leakage value with both light devices than in the groups where FS and HU were used, and a lower leakage value than A which has a similar flow consistency and no statistically significant difference was determined ( $p>0.05)$. Similarly, in a study examining microleakage of self-adhesive flow composites, Bektaș et al. found no statistically significant difference between VF and Optibond and Revolution Formula 2 Flow (17). Vichi et al. reported the least leakage from the use of Vertise ${ }^{\mathrm{TM}}$ Flow in an evaluation of self-adhesive flow composite resins and other flow composites in respect of microleakage (18). Kamal El-Din et al. examined 3 different pit and fissure overlays and determined the least leakage in the Vertise ${ }^{T M}$ Flow group (19).

The reasons for inconsistencies between the results of the current study and those of the studies of Vertise $^{\mathrm{TM}}$ Flow related to microleakage by Vichi et al. and Kamal El-Din et al. $(18,19)$, can be considered to be differences in methodology such as the other restorative materials selected, the use of light devices of different strengh, the location and manner of preparing the cavities, the type of teeth used (primarypermanent) or the methods used to determine leakage.

Another material used in the current study was $\mathrm{HU}$. In the occlusal edge in all 8 groups, this showed less leakage than VF, which had the highest leakage values and more than FS, which had the lowest values. In the gingival edge of all 8 groups, HU showed statistically significantly less leakage than, $\mathbb{E}$ and VF $(p<0.05)$, and a higher leakage value than FS $(p>0.05)$. In addition when $\mathrm{HU}$ was polymerised with both halogen and LED light devices, although greater microleakage was determined in both the occlusal and gingival edges compared to the FS groups, the difference was not statistically significant $(p>0.05)$.

Similar to the results of the current study, Sadeghi et al. reported no statistically significant difference between $\mathrm{HU}$ and other materials examined in respect of microleakage in class $\mathrm{V}$ cavities (20).

In the occlusal edge in all 8 groups, $\mathbb{E}$ showed less leakage than VF, which had the highest leakage values and more than FS, which had the lowest values. In the gingival edge of all 8 groups, $\mathbb{E}$ was determined with the highest microleakage values. In addition when $\mathbb{E}$ was polymerised with both halogen and LED light devices, the leakage values in the occlusal edge were lower than those of the VF group. This difference was found to be statistically significant when polymerisation was applied with a halogen light device $(p<0.05)$ but not with LED polymerisation $(p>0.05)$. In the gingival edge, when polymerisation was applied with both halogen and LED light devices, the material showing the greatst microleakage was determined to be $\mathbb{E}$.

In studies of microleakage which have used composite restorative materials in class $\mathrm{V}$ cavities, greater microleakage values have been reported to have been observed in the gingival edge than in the occlusal edge $(13,21,22)$. These results are thought to be due to the negative effects of the thin enamel layer at the gingival edge. In the gingival region, the alignment of the enamel prisms is irregular and different from the keyhole appearance. As the enamel is thinner than in other areas, the dentin is more fragile and the amount of peritubular dentin is greater, the tubule density is reduced in this area (23).

The results of the current study obtained as a result of comparison of leakage in the occlusal and gingival edges show a similarity to the results of many studies $(13,21,22,24)$ and the microleakage values in the gingival edge were found to be statistically significantly greater than those in the occlusal edge $(p=0.006)$.

In studies which have examined the depth of polymerisation, it has been reported that deeper polymerisation is achieved with high energy intensity $(25,26)$. In the current study, the halogen light device intensity was $800-1200 \mathrm{~mW} / \mathrm{cm} 2$ and the LED light was $1500 \mathrm{~mW} / \mathrm{cm} 2$. In the current study, differences in the microleakage scores were caused by the use of halogen and LED light devices for polymerisation of the same materials. No statistically significant difference was determined in either the occlusal or gingival edges between the halogen and LED light devices in Group 1, Group 2 and Group 4 ( $p>0.05)$. These results of no difference found between the halogen and LED light devices in respect of microleakage are in parallel with the results of Cavalcante et al., Sadeghi and Duangthip et al. $(7,27,28)$.

In the current study, less leakage was observed in the occlusal edge only in Group 3 polymerised with LED light device and a statistically significant difference was determined between the halogen and LED light devices $(p=0.042)$. In our study, lower microleakage values were obtained in Group 3 with polymerisation by LED light device and this was seen to be similar to the findings of studies by Oberholzer et al., Bodrumlu et al. and Yilmaz et al. (29-31).

\section{Conclusions}

As the values of $\mathrm{HU}$ in respect of microleakage were seen to be close to those of the best performing material, FS, it was evaluated as successful. Both of these restorative materials can be considered suitable for selection for Class $\mathrm{V}$ restorations in primary molar teeth.

In respect of ease of application, the self-adhesive flow composite resin, VF, is advantageous in paeditric dentistry, but in the evaluation of microleakage based on the results of this study, the material was not seen to show the desired level of success. As similar findings 
were determined, in cases where the use of a flow composite resin, such as $\mathbb{E}$ is indicated, VF can be considered a good alternative.

There is a need for further in vivo and in vitro studies with light devices and new restorative materials produced as a result of rapid advances in technology.

Ethical Approval: Ethics committee approval was received for this study from Dicle University, Faculty of Dentistry Ethics Committee in accordance the World Medical Association Declaration of Helsinki, with the approval number: 2013/1.

Peer-review: Externally peer-reviewed.

Author Contributions: Conception - A.G.; Design - A.G., E.C.T.; Supervision - E.C.T.; Materials - A.G.; Data Collection and/or Processing - A.G., E.C.T.; Analysis and/or Interpretation - A.G.; E.C.T.; Literature Review - A.G.; E.C.T.; Writer - A.G.; Critical Review - E.C.T.

Conflict of Interest: No conflict of interest was declared by the authors.

Financial Disclosure: The authors declared that this study has received no financial support.

\section{References}

1. Alani AH, Toh CG. Detection of microleakage around dental restorations: a review. Operative Dentistry 1997;22(4):173-85.

2. Dayangaç GB. Kompozit Restorasyonlar, 2. Basım, İstanbul, 2011, Quintessence Yayıncılık, 1-82.

3. Ozturk AN, Usumez A, Ozturk B, Usumez S. Influence of different light sources on microleakage of class $\mathrm{V}$ composite resin restorations. J Oral Rehabil 2004;31:500-504.

4. Kleverlaan CJ, Feilzer AJ. Polymerization shrinkage and contraction stress of dental resin composites. Dental Materials 2005;21:1150-1157. (Crossref)

5. Silveira de Araújo C, Incerti da Silva T, Ogliari FA, Meireles SS, Piva E, Demarco FF. Microleakage of seven adhesive systems in enamel and dentin. The Journal of Contemporary Dental Practice 2006;7(5):26-33. (Crossref)

6. Özok AR, De Gee AJ, Wu MK, Wesselink PR. The influence of resin composite and bonded amalgam restorations on dentine permeability in class II cavities in vitro. Dental Materials 2001;17:477-484. (Crossref)

7. Cavalcante LM, Peris AR, Ambrosano GM, Ritter AV, Pimenta LA. Effect of photoactivation systems and resin composites on the microleakage of esthetic restorations. The Journal of Contemporary Dental Practice 2007;8(2):70-79. (Crossref)

8. Dos Santos RA, Lima AF, Soares GP, Ambrosano GMB, Marchi GM, Lovadino JR, Aguiar FHB. Effect of preheating resin composite and light-curing units on the microleakage of class II restorations submitted to thermocycling. Operative Dentistry 2011;36(1):60-65. (Crossref)

9. Bektas OO, Eren D, Akın GG, Sağ BU, Ozcan M. Microleakage effect on class $V$ composite restorations with two adhesive systems using different bleaching methods. Acta Odontol Scand 2013;71(3-4):1-8. (Crossref)

10. Rueggeberg FA. State-of-the-art: dental photocuring-a review. Dental Materials 2011:27(1):39-52. (Crossref)

11. Weinmann W, Thalacker C, Guggenberger R. Siloranes in dental composites. Dental Materials 2005;21:68-74. (Crossref)

12. Poureslami HR, Sajadi F, Sharifi M, Ebrahimi SF. Marginal microleakage of low-shrinkage composite silorane in primary teeth: an in vitro study. Journal of Dental Research Dental Clinics Dental Prospects 2012;6(3):94-97.

13. Krifka S, Federlin M, Hiller KA, Schmalz G. Microleakage of silorane-and methacrylate-based class $\mathrm{V}$ composite restorations. Clinical Oral Investigations 2012;16(4):1117-1124. (Crossref)

14. Hooshmand T, Tabari N, Keshvad A. Marginal leakage and microhardness evaluation of low-shrinkage resin-based restorative materials. General Dentistry 2013;61(1):46-50.

15. Boutsiouki C, Tolidis K, Panagiotidou E. Effect of surface preparation and shade selection on microleakage of resinous pit and fissure sealants. Access date: 10 March 2020. (Weblink)

16. Eliades A, Birpou E, Eliades T, Eliades G. Self-adhesive restoratives as pit and fissure sealants: A comparative laboratory study. Dental Materials 2013;29(7):752-762. (Crossref)

17. Ozel Bektas O, Eren D, Akin EG, Akin H. Evaluation of a selfadhering flowable composite in terms of micro-shear bond strength and microleakage. Acta Odontol Scand 2013;71(34):541-546. (Crossref)

18. Vichi A, Margvelashvili M, Goracci C, Papacchini F, Ferrari M. Bonding and sealing ability of a new self-adhering flowable composite resin in class I restorations. Clinical Oral Investigations 2013;17:1497-1506. (Crossref)

19. El Motayam KEDM, Fouad WA, Youssef R. Assessment and comparison of nanoleakage and resin tag length of three different pit and fissure sealants: an in-vitro scanning electron microscope study. Journal of American Science 2013;9(5):329 337.

20. Sadeghi M, Davari A, Lynch CD. The effect of re-bonding using surface sealant or adhesive system on microleakage of class $V$ resin composite restorations. Dental Research Journal 2013;10(5):596-601.

21. Khier S, Hassan K. Efficacy of composite restorative techniques in marginal sealing of extended class $v$ cavities. ISRN dentistry 2010;2011:1-5. (Crossref)

22. Chandra PR, Harikumar V, Ramkiran D, Krishna M, Gouda MV. Microleakage of class $v$ resin composites using various selfetching adhesives: an in vitro study. The Journal of Contemporary Dental Practice 2013;14(1):51-55. (Crossref)

23. Altun $C$, Güven $G$, Başak $F$, Akbulut $E$. Süt diși sınıf $V$ kavitelerde akıșkan kompomer uygulamasının mikrosızıntı üzerine etkileri. Dicle Diș Hek Derg 2008;9(2):13-23.

24. Poggio C, Chiesa M, Dagna A, Colombo M, Scribante A. Microleakage in class $\mathrm{V}$ gingiva-shaded composite resin restorations. Annali Di Stomatologia 2012;3(1):19-23.

25. Halvorson RH, Erickson RL, Davidson CL. Energy dependent polymerization of resin-based composite. Dental Materials 2002;18:463-469. (Crossref)

26. Calheiros FC, Kawano Y, Stansbury JW, Braga RR. Influence of radiant exposure on contraction stress, degree of conversion and mechanical properties of resin composites. Dental Materials 2006;22:799-803. (Crossref)

27. Sadeghi M. Influence of flowable materials on microleakage of nanofilled and hybrid class II composite restorations with LED and QTH LCUs. Indian Journal of Dental Research 2009;20(2):159-163. (Crossref)

28. Duangthip D, Ballungpattama S, Sitthisettapong T. Effect of light curing methods on microleakage and microhardness of different resin sealants. Journal of Dentistry for Children 2011;78(2):88-95.

29. Yilmaz F, Gonulol N, Guler E, Ersoz E, Aytac F. Effects of different light sources on microleakage of composite resins with different monomer structures. Journal of Dental Sciences 2013;8:1-7.

30. Oberholzer TG, Schünemann M, Kidd M. Effect of LED curing on microleakage and microhardness of Class $V$ resin-based composite restorations. International Dental Journal 2004;54(1):15-20. (Crossref)

31. Bodrumlu E, Topuz O, Uzun O. Comparison of halogen versus led light-cured temporary endodontic filling materials for sealing. Minerva Stomatologica 2013;62(6):193-198. 